\title{
International Commission on Glass (ICG) Prepares for the New Decade ${ }^{1}$
}

\author{
New President Fabiano Nicoletti inaugurated at conference in Vancouver \\ DOI: $10.1134 / \mathrm{S} 1087659610040188$
}

At its annual conference held in Vancouver in June 2009 , the International Commission on Glass adopted a number of important fresh initiatives under its new President Fabiano Nicoletti. Key objectives for the future include greater globalization of activities and opening up the organization to more major glass companies.

Recent years have seen the effective reorganization of Technical Committee activities and the Coordinating Technical Committee by Klaus Bange; the successful completion of the important European project EFONGA by René Vacheg the creation of important Road Maps for future glass technology development by Ruud Beerkens and Wolfram Hoeland in particular; and a new modern ICG Constitution that opens up the organization to individuals and to international glass companies.

A number of important steps still need to be taken. First of all, it is agreed that all future ICG activities must be global. To achieve this goal, greater involvement of the BRIC countries: China, Brazil, Russia, and India is perceived to be vital. The first three of these have already pledged to contribute to the success of this new stage and will thus be assuming greater responsibility and taking on more duties within the framework of the ICG. The President Fabiano Nicoletti indicated that India will most likely follow suit. He noted that Europe, the United States, Japan, China, Russia, Brazil, and India need to interact in order to identify common objectives for the promotion of glass production and use, and the advancement of glass science and technology.

Greater involvement of the higher echelons of glass companies is also being encouraged by allowing them to participate directly in ICG decisions as a way of achieving continuous and effective interaction.

\footnotetext{
${ }^{1}$ The article was translated by the authors.
}

Furthermore, the effectiveness of the National Participating Organizations (NPOs) in representing their constituencies still needs to be verified. Their knowledge of and interaction with the national industrial glass community merits improvement. The NPOs should contribute toward the initiatives of the ICG and support them in an operational manner, for instance, by providing training teams, encouraging national glass production, identifying new and/or local financing sources and proposing new activities. Fabiano Nicoletti underlined that they should be the first vehicle for providing and disseminating information in their respective countries.

He requested that the Steering Committee Members become more active in all areas; for example, a teleconference for the Steering Committee would be organized every two months.

It was also agreed that the research activities of the ICG's Technical Committees need to be more oriented toward a modern Sustainable Low-Carbon Society (SLCS), in which high-tech glasses will be required to support energy saving and environmental protection initiatives. One key to the growth of glass applications will be a better understanding of glass surface and the development of more and more products that utilize thin-film technology. Furthermore, function-oriented glasses in combination with non-glass products need to be considered and examined. As Fabiano Nicoletti put it, "We should focus our attention on the areas with increasing demand, for instance, glass fibers, heat-resistant glass, glass for electronic devices, medical, biotech, generating energy savings and storage, and on the fundamental research necessary to prepare the next generation of glass products."

He also made it clear that, according to the constitution of the ICG, the art and history of glass should receive appropriate attention. An effort will now be made to verify and identify the existing international bodies in these fields that might be associated with the ICG. 